\title{
IMMUNOHISTOCHEMICAL LOCALIZATION OF CAFFEINE IN YOUNG CAMELLIA SINENSIS (L.) O. KUNTZE (TEA) LEAVES.
}

\author{
Shane V. van Breda ${ }^{1,2}$, Chris F. van der Merwe ${ }^{3}$, Hannes Robbertse ${ }^{4}$, Zeno Apostolides ${ }^{2}$ \\ ${ }^{2}$ Department of Biochemistry, ${ }^{3}$ Laboratory for Microscopy and Microanalysis, \\ ${ }^{4}$ Department of Plant Production and Soil Science, University of Pretoria, Lynnwood Road, \\ Hatfield, Pretoria, 0002, Gauteng, South Africa.
}

${ }^{1}$ Author for correspondence, e-mail: avbreda@iafrica.com. Telephone: (+27) 124202486. Fax: (+27) 123625302

Running title: VAN BREDA ET AL. - CAFFEINE LOCALISATION IN CAMELLIA SINENSIS.

Keywords: Caffeine, Camellia, freeze substitution, high pressure freezing, immunohistochemical, plant chemical defense.

Abbreviations: HPF: high-pressure freezing, FS: freeze substitution, FD: freeze drying, CSLM: confocal scanning microscopy, EtOH: ethanol, HPLC: high-performance liquid chromatography 


\begin{abstract}
The anatomical localization of caffeine within young Camellia sinensis leaves was investigated using immunohistochemical methods and confocal scanning laser microscopy. Preliminary fixation experiments were conducted with young $C$. sinensis leaves to determine which fixation procedure retained caffeine the best as determined by high-performance liquid chromatography analysis. High pressure freezing, freeze substitution and embedding in resin were deemed the best protocol as it retained most of the caffeine and allowed for the samples to be sectioned with ease. Immunohistochemical localization with primary anti-caffeine antibodies and conjugated secondary antibodies on leaf sections proved at the tissue level that caffeine was localized and accumulated within vascular bundles, mainly the precursor phloem. With the use of a pressure bomb, xylem sap was collected using a micro syringe. The xylem sap was analyzed by thin-layer chromatography and the presence of caffeine was determined. We hypothesize that caffeine is synthesized in the chloroplasts of photosynthetic cells and transported to vascular bundles where it acts as a chemical defense against various pathogens and predators. Complex formation of caffeine with chlorogenic acid is also discussed as this may also help explain caffeine's localization.
\end{abstract}

\title{
Introduction
}

Tea is the agricultural product of Camellia sinensis, utilizing the top youngest leaves of the plant. The chief teas of commerce are green tea, black tea, and oolong tea and in beverage form, it is the second most widely consumed product worldwide after water (Willson and Clifford 1992). The young leaves of C. sinensis contain catechins known for their beneficial health properties such as radical scavenging, antibacterial action, and prevention of cancer (Hara 
2001). A less popular compound is a xanthine alkaloid known as caffeine whose content is between 3 and $4 \%$ (based on dry weight) and is responsible for disturbances in sleep and caffeinism (Willson and Clifford 1992).

A theory that might explain the possible role of caffeine within young $C$. sinensis leaves is the chemical defense theory (Harborne 1994). It explains that compounds such as caffeine protect the soft tissue from beetles, insect larvae, and other similar types of herbivores. When the leaf is young and soft, it has the highest amount of caffeine; this is when it is most vulnerable to herbivory. For example, experiments have shown caffeine to be lethal, killing the larvae of the tobacco horn worm (Manduca sexta) at a dietary concentration of $0.3 \%$ (Nathanson 1984) or causing sterility in the beetle Callosobruchus chinensis at a concentration of $1.5 \%$ (Rizvi et al. 1980). As the leaf ages and hardens, due to cellulose and lignin deposits, it becomes less palatable to predators. The caffeine content decreases until the old leaves are almost caffeine free (Harborne 1994).

The enzyme responsible for caffeine synthesis is caffeine synthase, and its biosynthetic pathway is well documented (Dewick 2009). Caffeine synthase has been located within the chloroplasts of young leaves (Kato et al. 1998; Koshiishi et al. 2001) specifically thought to be in the stroma (Kato et al. 1999). Alkaloids in general do not show the same patterns of localization. For example, histochemical investigations for Lupinus luteus (Yellow Lupin) showed the highest alkaloid concentration to be in the spongy mesophyll cells (White and Spencer 1964). In Catharanthus roseus (Madagascar Periwinkle), immunocytochemical data showed the accumulation of vindoline to be in the sub-epidermal layers and mesophyll cells and compartmentalization was seen in the vacuoles of mesophyll cells and idioblasts (Brisson et al. 1992). Histochemical and immunocytochemical investigations for cocaine in Erythroxylum coca 
var. coca and E. novogranatense var. novogranatense (Coca plant) were determined to be within the photosynthetic layer. Positive reactions with Dragendroff's reagent were seen in the palisade, spongy, and vascular parenchyma. Staining was also seen in the xylem parenchyma and idioblasts of the collenchyma. Immunocytochemical data showed cocaine within the vacuoles of the photosynthetic tissue where it was suggested that the alkaloid exists in a vacuolar complex with phenolic compounds (Ferreira et al. 1998). In Vinca sardoa (Apocynaceae), histochemical tests were used to indicate the close relationship between alkaloids and laticifer cells (Sacchetti et al. 1999). The alkaloid ancistroheynine A was found in the tip of the shoot and leaf midrib of Liana Ancistrocladus heyneanus and ancistrocladine was found in the branch root of the plant by FT-Raman investigations (Urlaub et al. 1997). Many more articles are published describing the localization of different alkaloids with different techniques (Verzár - Petri 1975; Yoder and Mahlberg 1976; Furr and Mahlberg 1981; Neumann et al. 1983; Platt and Thomson 1992; Bringmann et al. 1996; Mösli Waldhauser and Baumann 1996; Meininger et al. 1997; Cai et al. 1999; Corsi and Bottega 1999; Bottega et al. 2004; Pasqua et al. 2004; Alcantara et al. 2005; Frosch et al. 2006, 2007a, b; Nikolakaki and Christodoulakis 2006; Mesjasz - Przybyiowicz et al. 2007; Liang et al. 2009; Moraes et al. 2009; Argyropoulou et al. 2010; Christodoulakis et al. 2010).

Microscopic detection of small molecules such as alkaloids in leaf material is extremely difficult as stated in previous localization studies (Ferreira et al. 1998). This is primarily due to standard fixatives which fix only proteins and lipids (Hayat 2000). At the same time, standard fixation disrupts permeability barriers in cells allowing for the movement of small molecules (Hayat 2000; Coetzee and van der Merwe 1984). Caffeine also has a high solubility in alcohol (1 $\mathrm{g}$ in $66 \mathrm{ml}$ ) (The Merck index 1976) making room temperature dehydration unfeasible. Thus, 
high-pressure freezing (HPF), freeze substitution (FS), or freeze drying (FD) are better alternatives due to a number of advantages (Steinbrecht and Zierold 1987).

Immunohistochemistry is useful in localizing small molecules (Brisson et al. 1992; Kim and Mahlberg 1997; Ferreira et al. 1998), as the technique is much more specific as opposed to standard histochemical methods using stains such as Dragendorff's reagent that are not specific for a small molecule but rather an entire class of small molecules such as alkaloids, and they are known to give false positives or side reactions (Pedersen 2006). Polyclonal antibodies are a better choice over monoclonal antibodies for immunohistochemistry since they are able to detect more than one epitope in the antigen. Small changes in the structure of the compound of interest due to fixation protocols usually will not affect binding affinity, and they react with structurally related compounds compared to the compound being localized (Ibrahim 1990; Ferreira et al. 1998).

By determining the localization of caffeine within young $C$. sinensis leaves, it will unlock valuable information regarding the biological role of the xanthine alkaloid.

Using HPLC for caffeine analysis and preliminary fixation experiments for chemical fixation, HPF/FS, and HPF/FD we could develop a fixation protocol that allowed caffeine to be retained within the leaf material during fixation as well as embedding protocols and thus its suitability for immunohistochemical investigations. By employing, a variety of controls caffeine was localized in young C. sinensis leaves using confocal scanning laser microscopy.

\section{Materials and methods}

Plant material 
Camellia sinensis (L.) O. Kuntze leaves of cv. PC105 were collected in the morning from our experimental farm at the University of Pretoria, Hatfield, South Africa. Old C. sinensis leaves were collected at the same time from the bottom of a cv. PC105 bush. Hedera helix L. (English Ivy) leaves were collected from the University of Pretoria's gardens in the morning. Average weights of young $C$. sinensis leaves and old $C$. sinensis leaves were determined after being dried at $103{ }^{\circ} \mathrm{C}$ for $48 \mathrm{~h}$.

Preparation of a decaffeinated tea leaf

The method used was according to Liang et al. (2006) where boiling young fresh tea leaves in water for 3 min removes $\pm 83 \%$ of caffeine content and only $\pm 5 \%$ of total catechins.

Preliminary fixation experiments

Young C. sinensis leaf material of $\pm 600 \mathrm{mg}$ was cut into pieces of $5 \mathrm{~mm}^{2}$. To simulate chemical fixation the leaf material was placed in $2.5 \%(\mathrm{v} / \mathrm{v})$ glutaraldehyde, $2.5 \%(\mathrm{v} / \mathrm{v})$ formaldehyde in $0.15 \mathrm{M}$ phosphate buffer (pH 7.4) for $2 \mathrm{~h}$. Samples were rinsed 3 x 5 min with phosphate buffer and then dehydrated with 30, 50, 70, 90 and $2 \times 100 \%$ ethanol (EtOH) (Saarchem, Krugersdorp, Gauteng, South Africa) 5 min each. To simulate HPF, samples were snap-frozen in liquid nitrogen and then either simulated for FS or FD. For FS, $100 \% \mathrm{EtOH}$ (precooled to $-70{ }^{\circ} \mathrm{C}$ ) was added to the frozen samples and kept at $-70{ }^{\circ} \mathrm{C}$ for 24 hours and then at $20{ }^{\circ} \mathrm{C}$ for 24 hours followed by $4{ }^{\circ} \mathrm{C}$ for 2 hours. For FD, samples were placed in a freeze drier (VIRTIS, Warminster, PA, USA) for $24 \mathrm{~h}$ or until dry. Once complete, samples were rinsed in $\mathrm{ddH}_{2} \mathrm{O}$ (except for FD samples), dried with paper towel and dried $\mathrm{O} / \mathrm{N}$ at $103{ }^{\circ} \mathrm{C}$ for HPLC 
analysis. Duplicate experiments were carried out on the same day, and two independent experiments were completed on different days.

\section{Moisture content determination}

Before moisture content was determined, samples were first dried over night at $103{ }^{\circ} \mathrm{C}$ and then ground up the next day with a mortar and pestle. Moisture content determination was according to ISO 1573. Standards used were either Lipton black tea or Lipton green tea bought at a local supermarket.

\section{Caffeine content determination by HPLC}

HPLC analysis was done according to ISO/CD 14502-2 and all chemicals used were of HPLC grade. Samples were extracted according to ISO/CD 14502-2 and diluted five times in stabilizing solution containing $10 \%(\mathrm{v} / \mathrm{v})$ acetonitrile (Merck) with $500 \mu \mathrm{g} / \mathrm{ml}$ EDTA (Sigma) and $500 \mu \mathrm{g} / \mathrm{ml} \mathrm{L-ascorbic} \mathrm{acid} \mathrm{(Sigma).} \mathrm{Ethyl} \mathrm{gallate} \mathrm{(Fluka)}(1 \mathrm{mg} / \mathrm{ml})$ was used as an internal standard and caffeine (Merck) was used as a standard at a concentration of $0.2 \mathrm{mg} / \mathrm{ml}$ dissolved in stabilizing solution. This was also used in the construction of a standard curve with $\mathrm{R}^{2}>0.98$. Bubbles were removed from vials using a vortex mixer, and the samples were placed in a 717 plus autosampler (Waters ${ }^{\mathrm{TM}}$, Milford, MA, USA) at $4{ }^{\circ} \mathrm{C}$. A flow rate of $1 \mathrm{ml} / \mathrm{min}$ was used and solvents ((A) $10 \%(\mathrm{v} / \mathrm{v})$ acetonitrile, $0.1 \%(\mathrm{v} / \mathrm{v})$ formic acid (Saarchem), and (B) $80 \%(\mathrm{v} / \mathrm{v})$ acetonitrile, $0.1 \%(\mathrm{v} / \mathrm{v})$ formic acid) were degassed using a sonicator and additionally sparged with helium gas at $30 \mathrm{ml} / \mathrm{min}$ during analysis. Gradient conditions were according to ISO/CD 14502-2 except that before resetting and end equilibration in $100 \% \mathrm{~A}, 100 \% \mathrm{~B}$ was used for 10 min first then reset to $100 \%$ A over 1 min and equilibrated for 10 min. A G600 series controller 
(Waters ${ }^{\mathrm{TM}}$ ), 600 pump (Waters ${ }^{\mathrm{TM}}$ ) and Luna $5 \mu \mathrm{m}$ Phenyl-Hexyl column (Phenomenex ${ }^{\circledR}$, Torrance, CA, USA) with dimensions $250 \mathrm{~mm}$ x $4.6 \mathrm{~mm}$ with a SecurityGuard ${ }^{\mathrm{TM}}$ Phenyl-Hexyl cartridge (Phenomene ${ }^{\circledR}$ ) with dimensions $4 \mathrm{~mm} \times 3 \mathrm{~mm}$ was used. The column was maintained at a temperature of $35^{\circ} \mathrm{C}$ using a column thermostat (Merck). The detector used was a 996 photodiode array detector (Waters ${ }^{\mathrm{TM}}$ ) with UV wavelengths set between $190 \mathrm{~nm}-500 \mathrm{~nm}$. Software used for data analysis was Empower ${ }^{\mathrm{TM}} 2$ version 6.2 (Waters ${ }^{\mathrm{TM}}$ ). Lipton green tea was used as a standard and analysis was completed in duplicate on the day, and two independent experiments were completed in each case.

\section{HPF/FS and embedding of samples}

From the leaf blade, discs of ca. $1.2 \mathrm{~mm}$ in diameter were cut using a HPF punch. Using a syringe, samples were vacuum infiltrated with 1-hexadecene (Merck). Samples were placed into the $200 \mu \mathrm{m}$ depression of Leica gold HPF planchettes, coated with $1 \% \mathrm{w} / \mathrm{v} \mathrm{L-} \alpha-$ phosphatidylcholine type X-E (Sigma,). The samples were frozen under high pressure in the sample holder of a Leica EM PACT2. Samples were then FS in a Leica EM AFS 2 system at a temperature of $-90{ }^{\circ} \mathrm{C}$. Once the liquid nitrogen had evaporated from the FS sample holders, $100 \%$ EtOH (Merck) pre-cooled to $-90{ }^{\circ} \mathrm{C}$ was added. Samples were freeze substituted in $100 \% \mathrm{EtOH}$ at $-90{ }^{\circ} \mathrm{C}$ for $12 \mathrm{~h}$ followed by warm-up at $5{ }^{\circ} \mathrm{C} \mathrm{h}^{-1}$ until $-30{ }^{\circ} \mathrm{C}$ was reached. Once at $-30{ }^{\circ} \mathrm{C}$, samples were carefully dislodged from their planchettes and infiltrated with Lowicryl K4M resin (Polysciences Inc, Eppelheim, Germany) and EtOH with the following ratios of 1:1, 2:1, and 3:1 for $1 \mathrm{~h}$ each followed by $100 \%$ resin for $24 \mathrm{~h}$ with two changes. A cross linker concentration of 
$18 \% \mathrm{w} / \mathrm{w}$ was used to make the resin. Samples were polymerized at $-30{ }^{\circ} \mathrm{C}$ for $72 \mathrm{~h}$ under UV light. Samples were embedded in triplicate over two independent embedding experiments.

\section{Confocal scanning laser microscopy of samples}

Resin blocks were sectioned at $5 \mu \mathrm{m}$ thickness with a dry glass knife using a Reichert Ultracut E Ultramicrotome. In all cases contact of the sections to water was kept to an absolute minimum. Once fixed to slides, samples were blocked for 1 hour in $2 \%(\mathrm{w} / \mathrm{v})$ BSA (Merck) or $2.5 \%(\mathrm{v} / \mathrm{v})$ Donkey serum (Sigma) dissolved in $1 \times \mathrm{PBS}(\mathrm{pH}$ 7.4) followed by labeling at room temperature with sheep polyclonal anti-caffeine Ig fraction (American Research Products, Inc, Waltham, MA, USA) at a dilution of 1:200 (v/v) for $1 \mathrm{~h}$. The cross-reactivity data of the antibody with related alkaloids was determined by the manufacturer to be as follows: $100 \%$ for caffeine, $100 \%$ for theophylline and $<1 \%$ for theobromine using polarization immunoassay. Samples were rinsed $3 \times 3 \mathrm{~min}$ in blocking buffer and $3 \times 3 \mathrm{~min}$ in $1 \times$ PBS. Samples were secondary labeled with donkey polyclonal anti-sheep IgG conjugated to DyLight ${ }^{\circledR} 488$ (AbD Serotec, Oxford, UK) at a dilution of 1:200 (v/v) for $1 \mathrm{~h}$ after which samples were rinsed. Above antibodies were always diluted according to manufacturer's specification. Samples were then mounted in antifade (Giloh and Sedat 1982) and then sealed with a cover slip and nail polish. Controls included samples labeled with no primary antibody in solution and labeled with primary antibody pre-adsorbed with caffeine. Other controls included the decaffeinated C. sinensis leaf, old C. sinensis leaf and, the H. helix leaf. Samples were then viewed using a Zeiss CSLM 510 META microscope. Two channels were used for analysis: $\mathrm{Ar} / \mathrm{Kr} 488 \mathrm{~nm}$ laser with a band pass between 505 and $530 \mathrm{~nm}$ (green) to detect the labeled antibody and a $\mathrm{He} / \mathrm{Ne} 543 \mathrm{~nm}$ laser with a long pass from $560 \mathrm{~nm}$ (red) to detect autofluorescence in the samples. A pin hole size of $\approx 70$ 
$\mu \mathrm{m}$ was also used when images were taken. Samples were viewed using a 40x water immersion lens and areas of interest were enlarged using the scan zoom (crop) function of Zeiss LSM 510 META software version 3.2 SP2. A Z series was taken for all images comprising of 10 and 40 optical slices being $\approx 1 \mu \mathrm{m}$ apart. Differential interference contrast (DIC) images were also taken of the areas of interest in the samples. Images were further edited using Image J (Abramoff et al. 2004).

\section{Light microscopy of samples}

Samples were stained with $0.2 \%(\mathrm{w} / \mathrm{v})$ Toluidine blue $\mathrm{O}$ in $0.5 \%$ sodium bicarbonate. Staining was 30 seconds at room temperature and sections were then rinsed with $\mathrm{ddH}_{2} \mathrm{O}$. Samples were then mounted in glycerol and viewed using a Nikon Optiphod transmitted light microscope attached with a Nikon DXM1200 digital camera. The software used was Nikon ACT-1 ver. 2. ImageJ was used for image processing.

\section{Editing of images with ImageJ software}

ImageJ 1.43j 32-Bit was used for image processing for CSLM images. Image stacks were converted to RGB and extended depth of field (EDF) easy (Forster et al. 2004) was used. If needed the transform function was used to rotate images or vertically flip them. A background subtraction for the images was done (separate colors), and a scale bar was added. Noise was reduced using the outlier function, and colors were enhanced if needed. 
A pressure bomb instrument was used, and the xylem sap from one or two C. sinensis shoots were collected using a micro syringe. Samples were place within the pressure bomb and pressure increased until xylem sap appeared or 200 psi was reached. Approximately $100 \mu$ of xylem sap was collected and spotted onto a silica gel 60 F254 TLC plate (Merck) using the syringe. Plates were developed according to Rogers et al. (1993) and visualized under U.V. This was conducted in duplicate on the day and over two independent experiments.

\section{Results}

Determination of the caffeine content in leaf samples and preliminary fixation experiments

The young leaves from $C$. sinensis were determined to contain $2.39 \pm 0.05 \%(\mathrm{w} / \mathrm{w})$ caffeine (Table 1). When these young leaves were decaffeinated, they resulted in a total reduction of $78 \%$ caffeine content. Our HPLC analysis revealed that there was no significant loss of catechins such as epigallocatechin gallate (EGCg) in the decaffeinated C. sinensis leaf when compared to the young leaf (data not shown). The old C. sinensis leaf contained $83 \%$ less caffeine when compared to the young leaf, and the Hedera helix leaf was determined to contain no caffeine. Our analysis also revealed that theophylline and theobromine were present in the young leaf in minimal concentrations when compared to caffeine, i.e. $0.44 \%(\mathrm{w} / \mathrm{w})$ and $0.03 \%$ $(\mathrm{w} / \mathrm{w})$, respectively these results confirmed the suitability of these samples as controls during CSLM analysis. Another interesting observation was the fact that-when the representative young tea leaf aged-its weight increased three times, while its caffeine content in grams decreases by $50 \%$ compared to the representative old leaf. 
Table 1 Caffeine analysis of different leaf materials

\begin{tabular}{llll}
\hline Leaf material. & $\begin{array}{lll}\text { Caffeine content }(\% \mathrm{w} / \mathrm{w}) \\
\text { mean } \pm \mathrm{SD} .\end{array}$ & $\begin{array}{l}\text { Average dry weight } \\
(\mathrm{mg}) \text { of leaf. }\end{array}$ & $\begin{array}{l}\text { Caffeine }(\mathrm{mg}) \text { per } \\
\text { dry leaf. }\end{array}$ \\
\hline Young C.sinensis & $2.39 \pm 0.05$ & 84.23 & 2.01 \\
leaves & & - & - \\
Decaffeinated & $0.53 \pm 0.04$ & & 0.98 \\
C.sinensis leaves. & & & \\
Old C.sinensis & $0.40 \pm 0.04$ & 245.1 & \\
leaves & & & \\
H.helix leaves. & $0.00 \pm 0.00$ & & \\
\hline -, not determined (negligible for conclusions) & & \\
\hline
\end{tabular}

The best fixation technique was determined to be HPF/FD since the young C. sinensis leaves retained $95 \%$ of their caffeine content (Table 2). Traditional chemical fixation was deemed the worst with only $23 \%$ of the caffeine content being retained. The method of HPF/FS was determined to retain $49 \%$ of its caffeine content. HPF/FS was used as the method of choice since difficulty in producing adequate sections with HPF/FD was continually encountered.

The localization of caffeine within young C. sinensis leaves

Caffeine was localized to the vascular area of young C. sinensis leaves (Fig. 1). The area that visually gave the highest level of fluorescence and thus the highest in concentration of caffeine was in the vascular bundles. The parenchyma cells did not visually show characteristics 
Table 2 Determination of caffeine lost with different preliminary fixation experiments

\begin{tabular}{lll}
\hline Fixation simulation & Caffeine content $(\% \mathrm{w} / \mathrm{w})$ & Retention of caffeine \\
mean $\pm \mathrm{SD}$. & $(\%)$. \\
\hline C.sinensis control & $3.86 \pm 0.06$ & - \\
Chemical fixation & $0.90 \pm 0.09$ & 23 \\
simulation & \\
HPF and FS simulation & $1.91 \pm 0.01$ & 49 \\
HPF and FD simulation. & $3.67 \pm 0.11$ & 95 \\
\hline -, not determined (negligible for conclusions)
\end{tabular}

of high caffeine accumulation. The young C. sinensis leaves vascular cells were not fully differentiated and thus made it difficult to determine the exact cells in which caffeine accumulates. The cells on the periphery of the vascular bundle (abaxial side) were seen to give strong levels of fluorescence. When using the scan zoom (crop) function of an area of cells with the characteristic green fluorescence it can be seen that the accumulation of caffeine was confined to the periphery of those cells with minimal fluorescence seen within the actual cell. Viewing DIC images it was suggested that the cells of accumulation would be the precursor phloem due to the young cells still under differentiation. The $543 \mathrm{~nm}$ channel with long pass detection (red) was used to give a better overall visualization of the cross sections as well as rule out any possibility of autofluorescence and thus false positives. As seen in Fig. 1, there is no overlap of red and green fluorescence in the areas determined to accumulate caffeine. Results from controls are displayed in Fig. 2. Young C. sinensis leaves labeled without secondary 

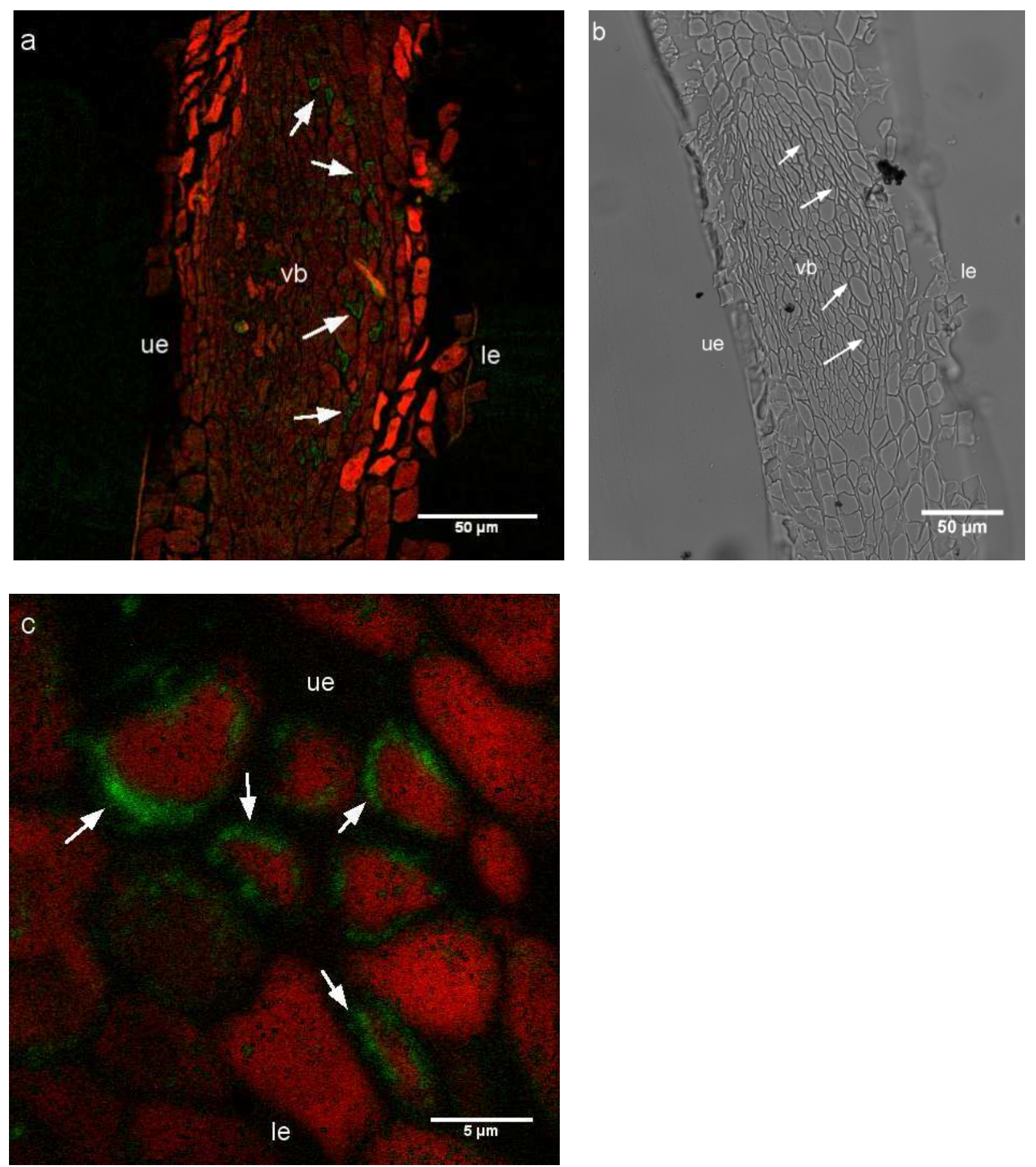

Fig. 1 Confocal and DIC micrographs of young C. sinensis leaf cross sections with indicated scale bars. a Micrograph taken with a $\times 40$ water immersion objective b DIC micrograph of the image in a. c Scan zoom (crop) function of an area of cells indicating a positive reaction; White arrows indicate areas of green fluorescence at the bottom of the vascular bundle $(v b)$ in the cross section and thus the localization of caffeine using immunolabeling. Upper epidermis of the cross section is indicated (ue) and the lower epidermis is indicated (le) 

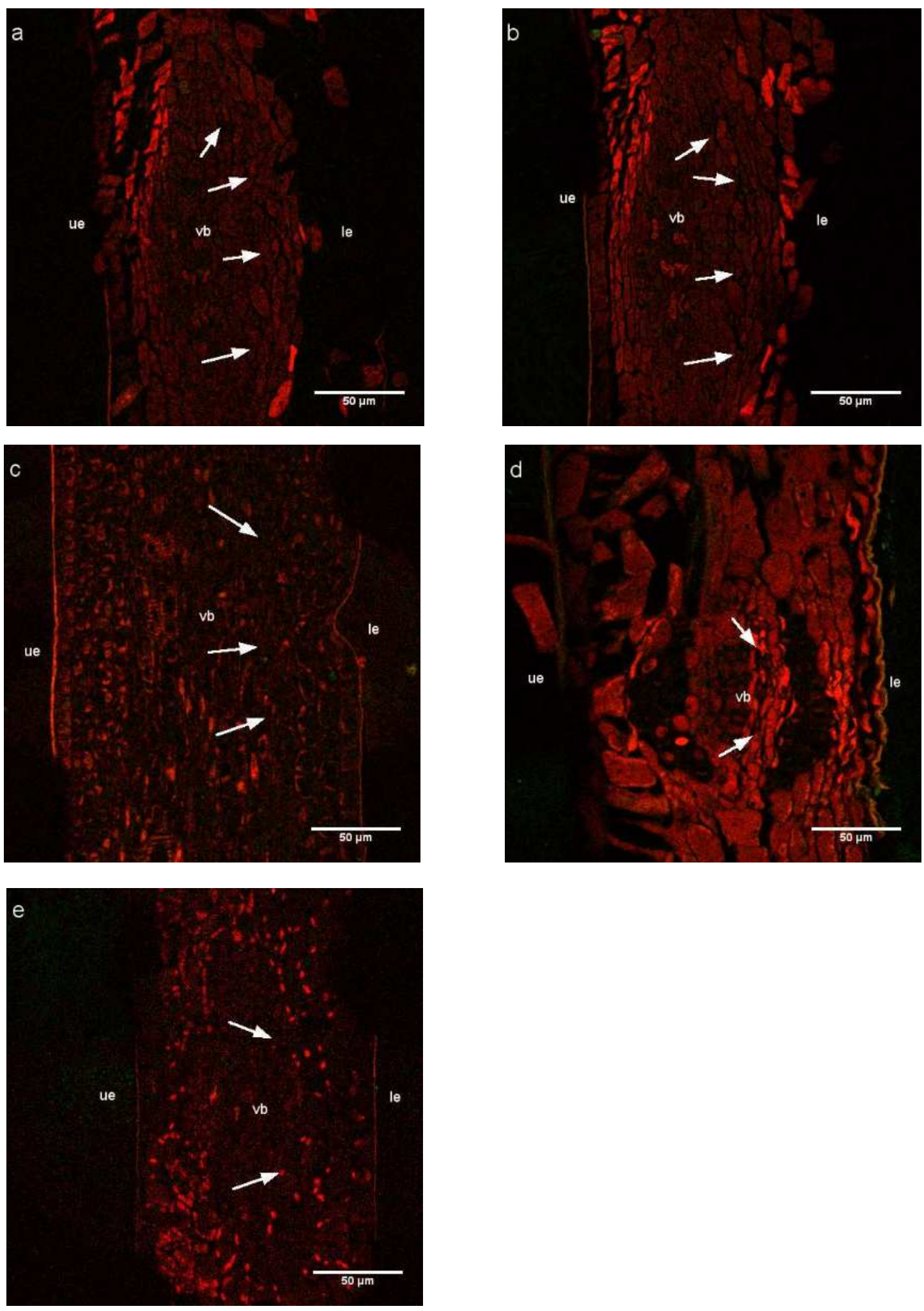

Fig. 2 Control confocal micrographs with indicated scale bars taken with a $\mathrm{x} 40$ water immersion objective. a Control was labeled without secondary antibody; $\mathbf{b}$ Control was labeled with primary antibody pre-adsorbed with caffeine; c Decaffeinated C. sinensis leaf; d Old C. sinensis leaf and e Young H. helix leaf. White arrows indicate areas where green fluorescence was previously observed in Fig. 1. Upper epidermis $(u e)$, vascular bundle $(v b)$ and lower epidermis $(l e)$ 

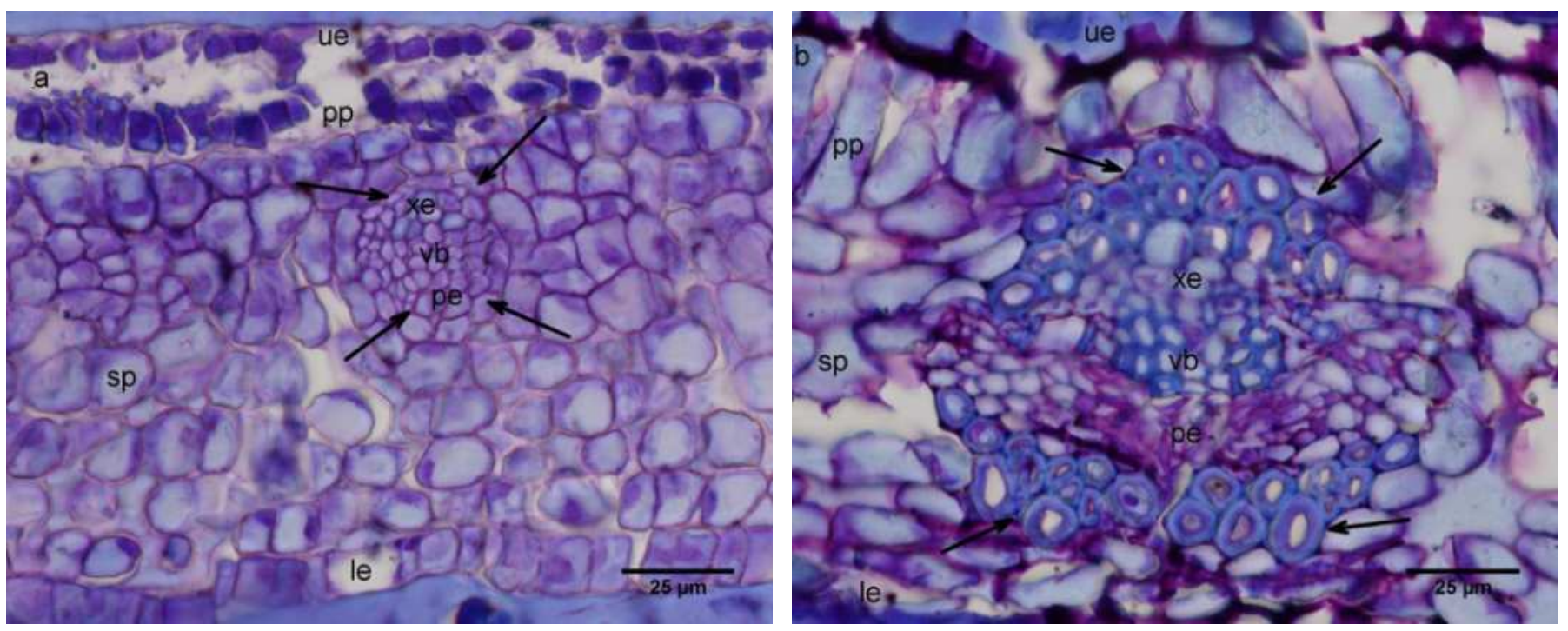

Fig. 3 Light micrographs of leaf cross sections stained with toluidine blue taken with a 440 oil immersion objective with indicated scale bar. $\mathbf{a}=$ young $C$. sinensis leaf, $\mathbf{b}=$ old $C$. sinensis leaf. Arrows in $\mathbf{a}$ indicate vascular areas of the periphery where the precursor xylem and phloem are located. Arrows in $\mathbf{b}$ indicate phloem fibers surrounding the vascular area. Upper epidermis $(u e)$, palisade parenchyma $(p p)$, vascular bundle $(v b)$, spongy parenchyma $(s p)$ and lower epidermis $(l e)$, xylem (xe) and phloem (pe)

antibody or with the primary antibody pre-adsorbed with caffeine were always negative. Other controls, i.e., the decaffeinated $C$. sinensis leaf (22\% caffeine), the old C. sinensis leaf (17\% caffeine content and the $H$. helix leaf ( $0 \%$ caffeine) were also always negative.

Undifferentiated young $C$. sinensis cells and differentiated old $C$. sinensis cells

The undifferentiated vascular bundle with precursor phloem and precursor xylem from a young $C$. sinensis leaf (Fig. 3) is indicated with arrows.

In the old C. sinensis leaf (Fig. 3) the differentiated cells around the periphery of the vascular bundle are fiber cells and contain highly lignified secondary cell walls. 
The caffeine standard control had a $R_{\mathrm{f}}=0.64$ and the xylem sap that was spotted onto the plate with the micro syringe and developed also had a spot with a $R_{f}=0.64$. There was a remarkable difference in the intensities of the relative spots. The control was very dark against the fluorescence background of the TLC plate while the spot from xylem sap considerably fainter. Even though the spot was considerably fainter, there was still a detectable amount of caffeine present within the xylem sap that was spotted and developed.

\section{Discussion}

Chemical fixation was avoided due to the majority of caffeine being extracted. Previous work has shown that chemical fixation extracts compounds such as $\mathrm{Ca}, \mathrm{Mg}$, reducing sugars, and amino acids (Coetzee and van der Merwe 1984). Caffeine is also most likely to be extracted during fixation for a number of reasons such as osmotic effects on plant tissues (Coetzee and van der Merwe 1985; Coetzee and van der Merwe 1986, Coetzee and van der Merwe 1987). At room temperature, caffeine also dissolves more easily during dehydration coupled with the effects of permeability disruption and unwanted osmotic effects from aldehyde fixation (Hayat 2000) it makes the process unsuitable when localizing small compounds such as caffeine, thus the methods of HPF and FS or FD were better choices due to avoidance of these unwanted effects (Steinbrecht and Zierold 1987). FD procedure removed only $5 \%$ of caffeine due to the fact that the sample never comes into contact with alcoholic dehydration. But without alcoholic dehydration, resin infiltration was extremely difficult or impossible, since such an alcoholic dehydration was needed to adequately infiltrate the sample with resin. Therefore, FS methods were preferably used. When FS takes place at a temperature below $-30{ }^{\circ} \mathrm{C}$ the solubility of caffeine in alcohol is reduced allowing for its retention within the sample, and this dehydration 
allowed for better infiltration of the resin into the sample thus producing better cross sections for microscopic analysis. Visual data of caffeine localization from the confocal micrographs correspond with the quantitative HPLC caffeine content analysis in the sense that samples with the highest level of fluorescence signal (caffeine content) to lowest are young $C$. sinensis leaves $>$ decaffeinated $C$. sinensis leaves $\geq$ old $C$. sinensis leaves $\geq H$. helix leaf (according to relative response intensities). This observation together with the antibody controls used, i.e., primary antibody excluded and primary antibody pre-adsorbed with caffeine, emphasize the high specificity that immunohistochemistry has for a specific antigen such as caffeine.

Using the young $C$. sinensis leaf for caffeine localization it was determined that accumulation was in the vascular bundle, mainly in the cells around the periphery (abaxial side). In some cases labeling was seen on the adaxial side, i.e., the precursor xylem, but controls revealed a certain level of autofluorescence thus giving ambiguous results (data not shown). Therefore, another method was required to confirm the presence of caffeine within the xylem cells. Using a pressure bomb and collecting the sap from the xylem caffeine was determined to be within these cells but in a low concentration. The concentration of caffeine within the precursor xylem cells seemed to be much lower than that of the precursor phloem cells as no detectable amount could be determined when using immunolabeling and CSLM analysis. TLC analysis revealed very low levels of caffeine present within the xylem sap suggesting its low concentration.

Photosynthetic cells, i.e., palisade and spongy parenchyma may also contain caffeine but in a much lower concentrations, i.e., undetectable amounts for immunolabeling and CSLM analysis. This result could be misleading as the area of palisade and spongy parenchyma is much larger when compared to the vascular area. Thus, a large proportion of caffeine may be 
distributed over this area as opposed to the smaller vascular area where caffeine is concentrated giving a higher fluorescence signal. Another possibility could be the fact that half of caffeine is extracted during the fixation and embedding process thus giving a lower concentration of the molecule within sections and producing undetectable amounts within the parenchyma cells. It is possible that the extraction might be uniform thus suggesting that the sites of detectable accumulation are within the vascular areas.

The old $C$. sinensis leaf has a low caffeine content since the leaf tissue has differentiated and become highly lignified and is thus no longer vulnerable to predators. The old leaf is approximately three times larger in mass than the young leaf and contains approximately half the caffeine (in grams). It is likely that caffeine synthesis has halted and the alkaloid is catabolized and recycled as the nitrogen could be used for de novo biosynthesis of caffeine in young leaves or in protein synthesis (Harborne 1994). Since the leaf contains a lower amount of caffeine and is much larger in size compared to the young leaf, there is a 'dilution' of caffeine over a larger area accounting for the reduction in signal.

The cells in the young vascular bundle where caffeine is located in are to differentiate into xylem and phloem cells surrounded by fiber cells. As the leaf ages and the fiber cells become fully developed, there is a less of a need for caffeine as a chemical defense and thus its reduction in the old leaf. It is possible that caffeine may be transported in the precursor xylem and precursor phloem in response to abiotic and biotic stress as mentioned previously for $C$. canephora leaves (Mondolot et al. 2006). Literature has suggested the localization of alkaloids in the vascular area, i.e. caffeine in C. canephora leaves was suggested to be localized to the phloem cells (Mondolot et al. 2006), swainsonine was determined to be in the phloem of Astragalus lentiginosus (locoweed) (Dreyer et al. 1985) and with regards to the xylem, tropane 
alkaloids were localized in the xylem cells of roots of Duboisia myoporoides (Khanam et al. 2000) or that quinolizidine alkaloids were located in the xylem of the Lupinus albus (White Lupin) (Bäumel et al. 1995). This localization probably functions as a chemical defense protecting the plant from sap sucking insects such as aphids (Dreyer et al. 1985). Caffeine may also protect against certain pathogens in the vascular area such as fungi as it has been determined that Puccinia poarum invades the vascular bundles of Tussilago farfara L. leaves (Coltsfoot) (Al Khesraji et al. 1980). Thus even though this explanation is a hypothesis and still needs to be proven, it is possible for caffeine to act as a defense against sap sucking insects and pathogens that infiltrate via the vascular system.

Another possible explanation for caffeine's localization in addition to acting as a chemical defense is its association with chlorogenic acid. Caffeine has been suggested to form complexes with chlorogenic acid (a caffeoylquinic acid) (Spencer et al. 1988; Mösli Waldhauser and Baumann 1996; Mondolot et al. 2006). Mondolot et al. (2006) works were performed on Coffea canephora leaf development and it was determined that caffeine was present within phloem cells in association with caffeoylquinic acids and most likely chlorogenic acid due to the compound being in very high concentrations in young leaves. Mondolot's localization of caffeine confirms our results, and it is most likely that caffeine is also in association with chlorogenic acid within the precursor phloem of young C. sinensis leaves. This does need confirmation and can be confirmed by microscopy using Neu's reagent (Neu 1957) and viewed using UV light and observe for a greenish white fluorescence (Mondolot-Cosson et al. 1997; Mondolot et al. 2006). Hypothesizing that caffeine is in complex with chlorogenic acid within the vascular bundle and using a suggestion from the authors (Mondolot et al. 2006) the transportation of caffeine from chloroplasts may be explained. Caffeoylquinic acid synthesis was 
suggested to take place within chloroplasts (same as caffeine) and then accumulated within vacuoles. From the vacuoles, the compounds are transported to vascular bundles where caffeine may act as a chemical defense and chlorogenic acid an intermediate in formation of highly lignified fiber cells observed in the old C. sinensis leaf. The complex formation of caffeine and chlorogenic acid may have aided in the compounds localization as it possibly acts as a natural fixative for the molecule.

Since caffeine was visually determined to be on the periphery of cells, it might be possible that the molecule might be bound or in complex with cell wall phenolics. During the immunolocalization protocol, free caffeine might be washed out easily. Thus, tissues such as leaf mesophyll that contain less cell wall phenolics will contain a weaker signal as they will retain less caffeine. Determining the amount of caffeine retained after the immunlocalization protocol will help establish the total proportion of caffeine retained and thus visualized within the relevant localized tissues.

\section{Acknowledgments}

We are grateful to Alan Hall and Andre Botha from the laboratory for microscopy and microanalysis at the University of Pretoria for all their microscopy knowledge and assistance.

\section{References}

Abramoff MD, PJ Magalhaes, SJ Ram (2004) Image processing with ImageJ. Biophotonics Int $11: 36-42$

Alcantara J, DA Bird, VR Franceschi, PJ Facchini (2005) Sanguinarine biosynthesis is associated with the endoplasmic reticulum in cultured opium poppy cells after elicitor treatment. 
Plant Physiol 138:173-183

Al Khesraji TO, DM Lösel, JL Gay (1980) The infection of vascular tissue in leaves of Tussilago farfara L. by pycnial-aecial stages of Puccinia poarum Niel. Physiol Plant Pathol 17:193-197 Argyropoulou C, A Akoumianaki - Ioannidou, NS Christodoulakis, C Fasseas (2010) Leaf anatomy and histochemistry of Lippia citriodora (Verbenaceae). Aust J Bot 58:398-409 Bäumel P, WD Jeschke, N Rath, F-C Czygan, P Proksch (1995) Modelling of quinolizidine alkaloid net flows in Lupinus albus and L. albus and the parasite Cuscuta reflexa: new insights into the site of quinolizidine alkaloid synthesis. J Exp Bot 46:1721-1730

Bottega S, F Garbahj, AM Pagni (2004) Hypericum elodes L. (Clusiaceae): The secretory structures of the flower. Isr J Plant Sci 52:51-57

Bringmann G, D Koppler, B Wiesen, G Francois, AS Sankara Narayanan, MR Almeida, H Schneider, U Zimmermann (1996) Ancistroheynine A, the first 7,8' - coupled naphthylisochinoline alkaloid from Ancistrocladus heyneanus. Phytochemistry 43:1405-1410 Brisson L, PM Charest, V De Luca, RK Ibrahim (1992) Immunocytochemical localization of vindoline in mesophyll protoplasts of Catharanthus roseus. Phytochemistry 31:465-470 Cai X, H Wu, ZH Hu (1999) Histochemistry of sinomenine in the stem of Sinomenium acutum and Sinomenium acutum var. cinerum (Chinese). Acta Bot Boreat - Occident Sin 19:104-107 Christodoulakis NS, S Kogia, D Mavroeid, C Fasseas (2010) Anatomical and histochemical investigation of the leaf of Teucrium polium, a pharmaceutical sub-shrub of the Greek phryganic formations. J Biol Res - Thessalon 14:199-209

Coetzee J, CF van der Merwe (1984) Extraction of substances during glutaraldehyde fixation of plant cells. J Microsc 135:147-158

Coetzee J, CF van der Merwe (1985) Effect of glutaraldehyde on the osmolarity of the buffer 
vehicle. J Microsc 138:99-105

Coetzee J, CF van der Merwe (1986) The osmotic effect of glutaraldehyde-based fixatives on plant storage tissue. J Microsc 141:111-118

Coetzee J, CF van der Merwe (1987) Some characteristics of the buffer vehicle in glutaraldehyde-based fixatives. J Microsc 146:143-155

Corsi G, S Bottega (1999) Glandular hair of Salvia officinalis: new data on morphology localization and histochemistry in relation to function. Ann Bot - Lond 84:657-664

Dewick PM (2009) Medicinal natural products: a biosynthetic approach. Wiley, Chicester, UK Dreyer DL, KC Jones, RJ Molyneux (1985) Feeding deterrency of some pyrrolizidine, indolizidine, and quinolizidine alkaloids towards pea aphid (Acyrthosiphon pisum) and evidence for phloem transport of indolizidine alkaloid swainsonine. J Chem Ecol 11:1045-1051

Ferreira JFS, SO Duke, KC Vaughn (1998) Histochemical and immunocytochemical localization of tropane alkaloids in Erythroxylum coca var. coca and E. novogranatense var. novogranatense. Int J Plant Sci 159:492-503

Forster B, D van de Ville, J Berent, D Sage, M Unser (2004) Complex wavelets for extended depth-of-field: a new method for the fusion of multichannel microscopy images. Microsc Res Techniq 65:33-42

Frosch, T, M Schmitt, K Schenzel, JH Faber, G Bringmann, W Kiefer, J Popp (2006) In vivo localization and identification of the antiplasmodial alkaloid dioncophylline A in the tropical liana Triphyophyllum peltatum by a combination of fluorescence, near infrared fourier transform, and density functional theory calculations. Biopolymers 82:295-300

Frosch T, M Schmitt, T Noll, G Bringmann, K Schenzel, J Popp (2007a) Ultrasensitive in situ tracing of the alkaloid dioncophylline A in the tropical liana Triphyophyllum peltatum by 
applying deep - UV resonance Raman microscopy. Anal Chem 79: 986-993

Frosch T, M Schmitt, J Popp (2007b) In situ UV resonance Raman micro - spectroscopic localization of the antimalarial quinine in cinchona bark. J Phys Chem B 111:4171-4177.

Furr M, PG Mahlberg (1981) Histochemical analyses of laticifers and glandular trichomes in Cannabis sativa. J Nat Prod 44:153-159

Giloh H, JW Sedat (1982) Fluorescence microscopy: reduced photobleaching of rhodamine and fluorescein protein conjugates by n-propyl gallate. Science 217:1252-1255

Hara Y (2001) Green tea health benefits and applications. Marcel Dekker Inc, New York Harborne JB (1994) Introduction to ecological biochemistry. Academic Press, Boston Hayat MA (2000) Principles and techniques of electron microscopy: biological applications. Cambridge University Press, USA

Ibrahim RK (1990) Immunocytochemical localization of plant secondary metabolites and the enzymes involved in their biosynthesis. Phytochem Anal 1:49-59

ISO 1573 (1980) Tea - determination of loss in mass at $103^{\circ} \mathrm{C}$. Ref. No. ISO 1573-1980 (E). ISO Organization, Geneva

ISO/CD 14502-2 (2002) Tea-Methods for determination of substances characteristic of green and black tea-Part 2: determination of catechins in green tea-method using high performance liquid chromatography. ISO Organization, Geneva

Kato A, A Crozier, H Ashihara (1998) Subcellular localization of the N-3 methyltransferase involved in caffeine biosynthesis in tea. Phytochemistry 48:777-779

Kato M, K Mizuno, T Fujimura, M Iwama, M Irie, A Crozier, H Ashihara (1999) Purification and characterization of caffeine synthase from tea leaves. Plant Physiol 31:465-470

Khanam N, C Khoo, R Close, AG Khan (2000) Organogenesis, differentiation and 
histolocalization of alkaloids in cultured tissues and organs of Duboisia myoporoides $\mathrm{R} . \mathrm{Br}$ Ann Bot Lond 86:745-752

Kim ES, PG Mahlberg (1997) Immunochemical localization of tetrahydrocannabinol (THC) in cryofixed glandular trichomes of Cannabis (Cannabaceae). Am J Bot 84:336-342

Koshiishi C, A Kato, S Yama, A Crozier, H Ashihara (2001) A new caffeine biosynthetic pathway in tea leaves: utilization of adenosine released from the S-adenosyl-L-methionine cycle. FEBS Lett 499:50-54

Liang H, Y Liang, J Dong, J Lu, H Xu, H Wang (2006) Decaffeination of fresh green tea leaf (Camellia sinensis) by hot water treatment. Food chem 101:1451-1456

Liang Z, H Chen, Z Zhao (2009) An experimental study on four kinds of Chinese herbal medicines containing alkaloids using fluorescence microscope and microspectrometer. J Microsc - Oxford 233:24-34

Meininger M, R Stowasser, PM Jakob, H Schneider, D Koppler, G Bringmann, U Zimmermann, A Haase (1997) Nuclear magnetic resonance microscopy of Ancistrocladus heyneanus. Protoplasma 198:210-217

Mesjasz - Przybyiowicz J, A Barnabas, W Przybyiowicz (2007) Comparison of cytology and distribution of nickel in roots of Ni-hyperaccumulating and non-hyperaccumulating genotypes of Senecio coronatus. Plant Soil 293:61-78

Mondolot L, P La Fisca, B Buatois, E Talansier, A De Kochko, C Campa (2006) Evolution in caffeoylquinic acid content and histolocalization during Coffea canephora leaf development. Ann Bot-London 98:33-40

Mondolot-Cosson L, C Andary, D Guang-Hui, J-L Roussel (1997) Histolocalisation de substances phénoliques intervenant lors d'interactions plante-pathogéne chez le tournesol et la 
vigne. Acta Bot Gallica 144:353-362

Moraes TMS, CF Barros, SJS Neto, M Gomes, M Da Cunha (2009) Leaf blade anatomy and ultrastructure of six Simira species (Rubiaceae) from the Atlantic Rain Forest, Brazil. Biocell $33: 155-165$

Mösli Waldhauser SS, TW Baumann (1996) Compartmentation of caffeine and related purine alkaloids depends exclusively on the physical chemistry of their vacuolar complex formation with chlorogenic acids. Phytochemistry 42:985-996

Nathanson JA (1984) Caffeine and related methylxanthines: possible naturally occurring pesticides. Science 226:184-187

Neu R (1957) A new reagent for differentiating and determining flavones on paper chromatograms. Naturwissenschaften 43:82

Neumann D, G Krauss, D Gröger (1983) Indole alkaloid formation and storage in cell suspension cultures of Catharanthus roseus. J Med Plants Res 48:20-23

Nikolakaki A, NS Christodoulakis (2006) Histological investigation of the leaf and leaforiginating calli of Lavandula vera L. Isr J Plant Sci 54:281-290

Pasqua G, B Monacelli, A Valletta (2004) Cellular localisation of the anti-cancer drug camptothecin in Camptotheca acuminata Decne (Nyssaceae). Eur J Histochem 48:321-328

Pedersen O (2006) Pharmaceutical chemical analysis: methods for identification and limit tests. Taylor and Francis Group LLC, Florida

Platt KA, WW Thomson (1992) Idioblast oil cells of avocado: distribution, isolation, ultrastructure, histochemistry, and biochemistry. Int J Plant Sci 153:301-31

Rizvi SJH, SK Pandey, D Mukerji, SN Mathur (1980) 1,3,7-Trimethylxanthine, a new chemosterilant for stored grain pest, Callosobruchus chinensis (L). J Appl Entomol 90:378-381 
Rogers K, J Milnes, J Gormally (1993) The laser desorption/laser ionization mass spectra of some methylated xanthines and the laser desorption of caffeine and theophylline from thin layer chromatography plates. Int J Mass Spectrom 123:125-131

Sacchetti G, M Ballero, M Serafini, C Romagnoli, A Bruni, F Poli (1999) Laticifer tissue distribution and alkaloid location in Vinca sardoa (STEARN) Pign. (Apocynaceae), an endemic plant of Sardinia (Italy). Phyton-Ann Rei Bot A 39:265-275

Spencer CM, Y Cai, R Martin, SH Gaffney, PN Goulding, D Magnolato, TH Lilley, Haslam E (1988) Polyphenol complexation: some thoughts and observations. Phytochemistry 27:23972409

Steinbrecht RA, K Zierold (1987) Cryotechniques in biological and electron microscopy. Springer, New York

The Merck index (1976) An encyclopedia of chemicals and drugs. Merck and Co Inc, New Jersey

Urlaub E, J Popp, W Kiefer, G Bringmann, D Koppler, H Schneider, U Zimmerman, B Schrader (1997) FT-Raman investigation of alkaloids in the Liana Ancistrocladus heyneanus.

Biospectroscopy 4:113-120

Verzár - Petri G (1975) Alkaloid biosynthesis in plant tissue. Egypt J Pharm Sci 16:123-128. White HA, M Spencer (1964) The sites of alkaloid concentration in Lupinus luteus tissues. Can J Bot 42:1481-1485

Willson KC, MN Clifford (1992) Tea cultivation to consumption. Chapman and Hall, London Yoder LR, PG Mahlberg (1976) Reactions of alkaloid and histochemical indicators in laticifers and specialized parenchyma cells of Catharanthus roseus (Apocynaceae). Am J Bot 63:11671173 